\title{
Transgluteal access for computed tomography-guided percutaneous puncture of prostatic abscesses
}

\author{
Acesso transglúteo para punção percutânea de abscesso prostático guiada por tomografia \\ computadorizada

\section{Rômulo Florêncio Tristão Santos ${ }^{1, a}$, Reinaldo Santos Morais Neto ${ }^{1, b}$, Fábio Galvão Vidal ${ }^{1, c}$, Luiz Augusto Morelli Said ${ }^{2, d}$, Thiago Franchi Nunes ${ }^{1, e}$}

1. Universidade Federal de Mato Grosso do Sul (UFMS), Campo Grande, MS, Brazil. 2. Hospital Regional de Mato Grosso do Sul (HRMS), Campo Grande, MS, Brazil.

Correspondence: Dr. Thiago Franchi Nunes. Avenida Senador Filinto Müller, 355, Vila Ipiranga. Campo Grande, MS, Brazil, 79080-190. Email: thiagofranchinunes@gmail.com.

a. https://orcid.org/0000-0002-8679-7369; b. https://orcid.org/0000-0001-8278-7449; c. https://orcid.org/0000-0002-9956-7626; d. https://orcid.org/0000-0001-6681-5382; e. https://orcid.org/0000-0003-0006-3725.

Received 3 April 2019. Accepted after revision 13 June 2019.

\section{How to cite this article:}

Santos RFT, Morais Neto RS, Vidal FG, Said LAM, Nunes TF. Transgluteal access for computed tomography-guided percutaneous puncture of prostatic abscesses. Radiol Bras. 2020 Mai/Jun;53(3):171-172.

\section{INTRODUCTION}

Prostatic abscess is a rare clinical condition that can result in serious complications such as urosepsis and death if it is not properly diagnosed and treated ${ }^{(1)}$. Once the diagnosis is established, the standard treatment options are the administration of antibiotics, open perineal drainage, and transurethral resection of the prostatic abscess. Currently, however, minimally invasive procedures such as needle aspiration guided by imaging methods are well established in interventional radiology practice and are preferable to conventional methods, with low rates of complications and satisfactory therapeutic results ${ }^{(1-8)}$.

Percutaneous drainage of pelvic abscesses are challenging because of the interposition of a large number of anatomical structures. Consequently, various routes of access and drainage techniques have been described ${ }^{(2,9)}$. To ensure that the procedure is successful, it is vital to plan the access route, which requires detailed knowledge of the pelvic anatomy. There are five major routes to approach deep pelvic lesions ${ }^{(9)}$ : transabdominal (anterior and lateral), anterolateral extraperitoneal, transvaginal, transrectal, and transgluteal.

In transgluteal access, the patient is usually placed either in the prone position or in the lateral position. This technique is also known as transischial access, because the needle will pass through the greater sciatic foramen. When possible, the needle will transfix the sacrospinal ligament, located below the level of the piriform muscle, in order to avoid injuring blood vessels of the gluteal region and sacral plexus that are located anteriorly to the muscle. Lesions eligible for the employment of this technique are those posterior to the urinary bladder and adnexal masses ${ }^{(9,10)}$. This access has the advantage of avoiding piercing of the peritoneum, minimizing the risk of injury to bowel, bladder, and iliac vessels, and giving the needle stable access through a static muscle mass, free from the respiratory movements of the abdominal wall. The disadvantage lies in the use of the uncomfortable prone position, which complicates respiration and management of the anesthesia.

\section{PROCEDURE}

Reviewing imaging examinations before the procedure is of paramount importance for its technical success. To localize the prostatic abscess and plan a safe path for the puncture needle, the procedure should be based on the best anatomical definition.

Computed tomography-guided transgluteal access performed with the patient in the prone position (Figure 1 ), under local anesthesia, allows the surgeon to view the 17 -gauge aspiration needle from its insertion into the skin through to the pelvic cavity (Figure 2). The needle will

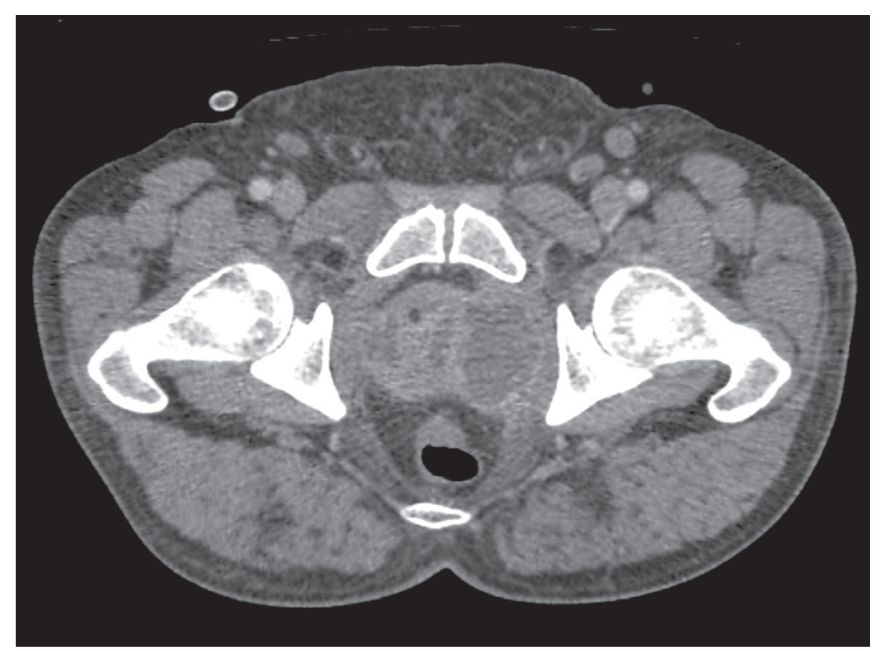

Figure 1. Axial contrast-enhanced computed tomography of the pelvis, showing a prostatic abscess. 


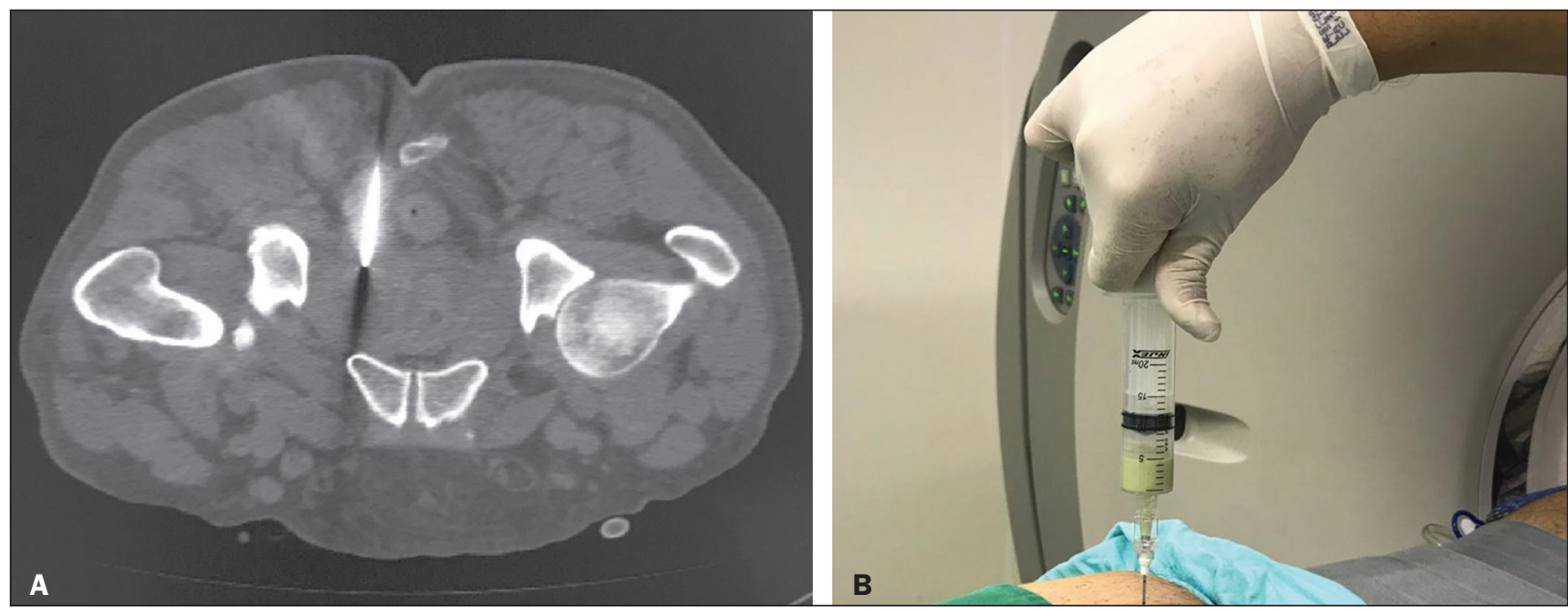

Figure 2. Computed tomography-guided transgluteal access performed with the patient in the prone position (A) and aspiration of purulent content (B).

pass through the greater sciatic foramen and transfix the sacrospinal ligament, located below the level of the piriform muscle, to avoid injuring blood vessels of the gluteal region and sacral plexus that are located anteriorly to the muscle $^{(9)}$. Although it is not a widely used technique, aspiration of the abscess contents, followed by flushing with $50 \mathrm{~mL}$ of $0.9 \%$ saline solution (using a Luer Lock $10 \mathrm{~mL}$ syringe) and antibiotic therapy, has a high success rate (Figure 3) and few complications when compared with transurethral resection of the abscess and perineal insertion of a large-caliber catheter for long-term drainage to control the residual infection ${ }^{(2,9-11)}$. The advantages of the former procedure include presenting fewer potential complications and being performed under local anesthesia and sedation, which minimizes the risks of adversities after general anesthesia, especially in severely ill patients,

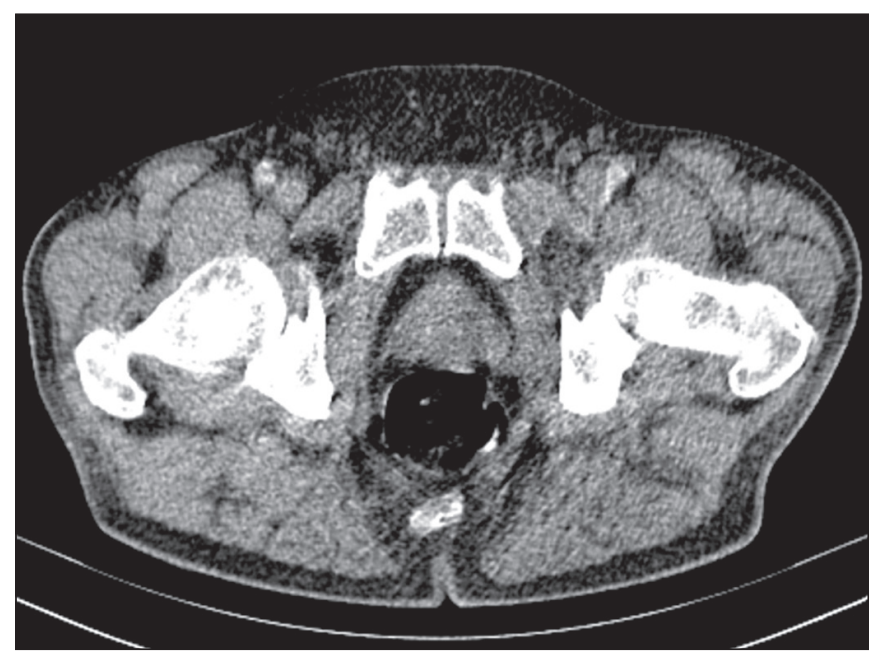

Figure 3. Computed tomography performed four weeks after the treatment, with no residual or new prostatic collections. as well as the possibility of repeating the procedure in the event of relapse. Ideally, it should be performed by interventional radiologists with training in percutaneous procedures $^{(9-11)}$.

\section{REFERENCES}

1. Jang K, Lee DH, Lee SH, et al. Treatment of prostatic abscess: case collection and comparison of treatment methods. Korean J Urol. 2012;53:860-4.

2. Garcia RG, Macedo Filho CL, Maurano A, et al. Image-guided percutaneous procedures in deep pelvic sites: review of the main approaches. Radiol Bras. 2008;41:343-8.

3. Schiavon LHO, Tyng CJ, Travesso DJ, et al. Computed tomographyguided percutaneous biopsy of abdominal lesions: indications, techniques, results, and complications. Radiol Bras. 2018;51:141-6.

4. Carneiro GAC, Arantes Pereira FP, Lopes FPPL, et al. Magnetic resonance imaging-guided vacuum-assisted breast biopsy: experience and preliminary results of 205 procedures. Radiol Bras. 2018;51: 351-7.

5. Tibana TK, Santos RFT, Arão Filho A, et al. Detection of additional primary malignancies: the role of $\mathrm{CT}$ and PET/CT combined with multiple percutaneous biopsy. Radiol Bras. 2019;52:166-71.

6. Tibana TK, Grubert RM, Camilo DMR, et al. Computed tomography-guided puncture using a mobile application for a motion sensor-equipped smartphone. Radiol Bras. 2019;52:245-6.

7. Nunes TF, Tibana TK, Santos RFT, et al. Percutaneous insertion of bilateral double J stent. Radiol Bras. 2019;52:104-5.

8. Tibana TK, Grubert RM, Santos RFT, et al. Percutaneous nephrostomy versus antegrade double-J stent placement in the treatment of malignant obstructive uropathy: a cost-effectiveness analysis from the perspective of the Brazilian public health care system. Radiol Bras. 2019;52:305-11.

9. Kuligowska E, Keller E, Ferrucci JT. Treatment of pelvic abscesses: value of one-step sonographically guided transrectal needle aspiration and lavage. AJR Am J Roentgenol. 1995;164:201-6.

10. Maher MM, Gervais DA, Kalra MK, et al. The inaccessible or undrainable abscess: how to drain it. Radiographics. 2004;24:717-35.

11. Gee MS, Kim JY, Gervais DA, et al. Management of abdominal and pelvic abscesses that persist despite satisfactory percutaneous drainage catheter placement. AJR Am J Roentgenol. 2010;194:815-20. 